\title{
Influences of Curing Environment on Strength Performances of Shanghai Clayey Soil Reinforced with Palm Fiber
}

\author{
Jili Qu $(\mathbb{D}$ and Kun Xiong \\ School of Environment and Architecture, University of Shanghai for Science \& Technology, Shanghai 200093, China \\ Correspondence should be addressed to Jili Qu; qujiliqwq@163.com
}

Received 18 November 2019; Accepted 14 February 2020; Published 17 March 2020

Academic Editor: Behzad Nematollahi

Copyright (C) 2020 Jili Qu and Kun Xiong. This is an open access article distributed under the Creative Commons Attribution License, which permits unrestricted use, distribution, and reproduction in any medium, provided the original work is properly cited.

\begin{abstract}
Owing to its environment-friendly, economically available, and sustainable property, the palm fiber was attempted to improve the quality of Shanghai clayey soil together with lime. The direct shear tests (DST), ultrasonic pulse velocity tests (UPV), and the unconfined compressive tests (UCT) have been carried out on soils mixed with palm fiber and lime under 3 curing conditions of immersion in water, cyclic wetting-drying, and air curing at a series of contents of additives. The corresponding indexes of shear strength $(\tau)$, cohesion $(c)$, internal friction angle $(\varphi)$, initial shear modulus $\left(G_{0}\right)$, and unconfined compressive strength $\left(q_{\mathrm{u}}\right)$ were obtained and analyzed. Results show that immersed-in-water environment is optimum for the formation of shear strength, initial shear modulus, cohesion, and unconfined compressive strength (UCS), while the air curing condition is the worst for admixture treated soil. Lime can increase $G_{0}$, but palm fiber can slightly reduce $G_{0}$. Lime has significant effect on increase of internal friction angle; on the contrary, palm fiber has only limited effect. $c / G_{0}$ for any type of sample remains almost constant under different curing conditions. It demonstrates that $c$ and $G_{0}$ possess the comparative development trend under different curing environment.
\end{abstract}

\section{Introduction}

Shanghai clayey soil is a type of soil that has special properties, for example, a low content of sand and gravel, the relatively small grain size, low permeability, high plasticity, very high moisture and void ratio, and high compressibility, which result in the low strength, and is vulnerable to deformation [1]. It had long been discovered that there is a deeply distributed layer of soft clayey soil in Shanghai area [2]. In addition, because of the microstructure characteristics in void and structural form, poor engineering features commonly exist with Shanghai clayey soil, of which high compressibility and low strength are most prominent for engineering construction [3]. In one word, Shanghai clayey soil cannot generally satisfy the requirements from geotechnical engineering construction before it is well processed. Therefore, many compacting methods have been attempted for the stabilizing of Shanghai natural soil, which have been involved in many types of admixtures commonly applied in soil enhancement with significant effects.
Over past several thousands of years, the grass root, wheat straw fiber, and so forth had long been used to mix with soils to improve the soil quality [4]. Many natural and artificial fibers, such as jute fiber, palm fiber, polypropylene fiber, and grass fiber, had been found to have the substantial ability of improving the compressive strength of soil [5]. Many investigations have been carried out on the shear strength property of different type of admixture-reinforced clayey soil under diverse conditions [6-12]. The unconfined compressive tests have also been carried out on reinforced soil to evaluate the influences of varied types of fibers on the unconfined compressive strengths of it [13, 14]. In addition, the ultrasonic pulse velocity technology has increasingly been used in the evaluation of mechanical performance of soil and concrete in recent decades [15-18].

Many researches were focused on the mechanical qualities of soils reinforced with cement or lime cured in a humid condition [19-29]. However, a large number of factors are known to affect the mechanical properties of treated soils [30]. 
So far, there is very limited information available on the impact of desiccation (air drying) on the shear strength and shear modulus at small or very small strain of soil stabilized by lime and palm fiber. Palm fiber is a green and renewable plant fiber. Making use of it in civil engineering industry is conformed with the trend of environment protection in the modern world. What is more, it is abundantly available and cheap in economy in immense southern area of China. In addition, palm fiber was also found to have a lot of strength characteristics when it was used for admixture in stabilizing the soil, such as being not susceptible to worm-biting and moldy and possessing strong elasticity and tenacity [31]. Therefore, the purpose of this work is to investigate the effects of different curing conditions (immersion in water, cycles of wetting and drying, and air curing) on the strength characteristics of soil samples treated with pulverized lime (mainly used as a binder) and palm fiber. The data obtained from the study are expected to provide fundamental basis for construction and design in civil engineering.

\section{Materials and Methods}

2.1. Materials. The soil employed in the research is a typical Shanghai clayey soil, which is obtained from an engineering site in Zhangjiang high-tech park of Pudong New Area, Shanghai, China. The physical and water-physical properties of the soil are presented in Table 1 . The gradation curve of Shanghai clayey soil used in this investigation is presented in Figure 1 [32]. The particle group less than $0.075 \mathrm{~mm}$ in size in Shanghai clayey soil accounts for approximately $60 \%$. The Shanghai clayey soil has a liquid limit of $42 \%$ and a plastic index of $22[24,33]$. Because the plastic index is greater than 17 , it is classified as clay. The lime employed in the research is a pulverized powder, which is commercially obtained and contains nearly $75 \%$ of $\mathrm{CaO}$ in weight. Table 2 displays the physical and chemical indexes of the lime. The gradation curve of the lime powder is also shown in Figure 1. The palm fiber employed in the investigation is commercially obtained from a forestry materials company located in west area of Shanghai. The palm fiber has a tensile strength range from 87 to $166 \mathrm{MPa}$, with a natural elongation range from 5 to $21 \%$. The key physical and mechanical properties of palm fiber employed in the experiment are shown in Table 3.

2.2. Sample Preparation. Soil-lime or soil-lime-palm fiber mixing in the laboratory was performed using a mortar mixer. The sample preparation method used is similar to the procedures recommended in many soil mixing reference guides [34, 35]. Firstly, the appropriate amount of dry soil and pulverized lime were manually mingled in the container until a visually homogeneous mixture was obtained. Then, the specified length and content of palm fiber are added to the mixture. They are randomly mixed until the mixture is homogeneous. Finally, the amount of tap water calculated based on Table 4 was added. Then the mixture was mixed for $10 \mathrm{~min}$.

For direct shear test, the mixture was then poured into cylindrical molds of $100 \mathrm{~mm}$ in height and $80 \mathrm{~mm}$ in diameter. The mixture of soil-lime-palm fiber was compacted in 3 layers by lightly tapping the molds on a horizontal surface to reduce the amount of trapped air bubbles. Then the soil column inside the cylinder was pushed out with an earth-moving device. The soil column was vertically placed on a table with smoothing the two ends. A cutting ring with vaseline being applied inside is employed to press vertically down on the top of soil column, then trimming the two extremities [36]. Finally, the top and bottom of the cutting ring were wrapped closely by preservative film to prevent the loss of moisture and soil particles on the surface of sample in the operation. The samples together with their cutting rings were then immediately stored in water bath at a constant temperature of $20^{\circ} \mathrm{C}$. The samples will be demolded just before direct shear test, which will be carried out according to test scheme as shown in Figure 2(a).

For unconfined compressive test, the mixes were then poured into cylindrical molds of $80 \mathrm{~mm}$ in height and $39 \mathrm{~mm}$ in diameter. A matching collar of about $27 \mathrm{~mm}$ in height was used to help prepare the sample. The mixture of soil-limepalm fiber was compacted in 3 layers by lightly tapping the molds on a horizontal surface to reduce the amount of trapped air bubbles. Their extremities were cut and smoothed to a height-to-diameter ratio of approximately 2 ( $80 \mathrm{~mm}$ in height $\times 39 \mathrm{~mm}$ in diameter). Then the top and bottom of the mold loaded with sample were wrapped closely by preservative film to prevent the loss of moisture and soil particles on the surface of sample in the operation. The samples together with their molds were then immediately stored in tap water at a constant temperature of $20^{\circ} \mathrm{C}$. Because the ultrasonic pulse velocity (UPV) test is nondestructive, the samples will be demolded just before UPV. The UCT will be done immediately after UPV, which will be carried out according to test scheme as shown in Figure 2(b).

2.3. Experimental Program. The test arrangement is given in Table 4. Three types of sample (nos. 1-3) were prepared for testing. The contents of lime, water content, and water-lime ratio were determined based on [18] and palm fiber was arranged according to [14]. The lime content $=$ (weight of dry lime)/(weight of dry soil), water content of sample $=($ weight of water $) /($ weight of dry soil + weight of dry lime + weight of palm fiber $)$, and water-lime ratio $=($ weight of water)/(weight of dry lime).

2.3.1. Direct Shear Test. The direct shear tests (DST) on the soil, soil-lime, and soil-lime-palm fiber mixtures were carried out to evaluate the shear performance of shear strength, cohesion, and internal friction angle of samples. The apparatus used is a quadruple equal-strain direct shear equipment (DJY-4L) manufactured by Nanjing Hydraulic and Electric Instrument Engineering Co., Ltd. The shear process is controlled by a constant shear velocity of $0.8 \mathrm{~mm} /$ min. The shear process will stop when shear deformation arrives at $10 \mathrm{~mm}$. The normal stresses used are 100, 200, and $400 \mathrm{kPa}$, respectively. The readings were recorded once every 15 seconds. 
TABle 1: Physical and water-physical properties of Shanghai clayey soil.

Liquid limit (\%) $\quad$ Plastic limit (\%) $\quad$ Plastic index $\quad$ Optimum water content (\%) $\quad$ Max. dry density $\left(\mathrm{g} \cdot \mathrm{cm}^{-3}\right) \quad$ Relative density of soil

\begin{tabular}{llllll}
\hline 42 & 20 & 22 & 20 & 1.62 & 2.73 \\
\hline
\end{tabular}

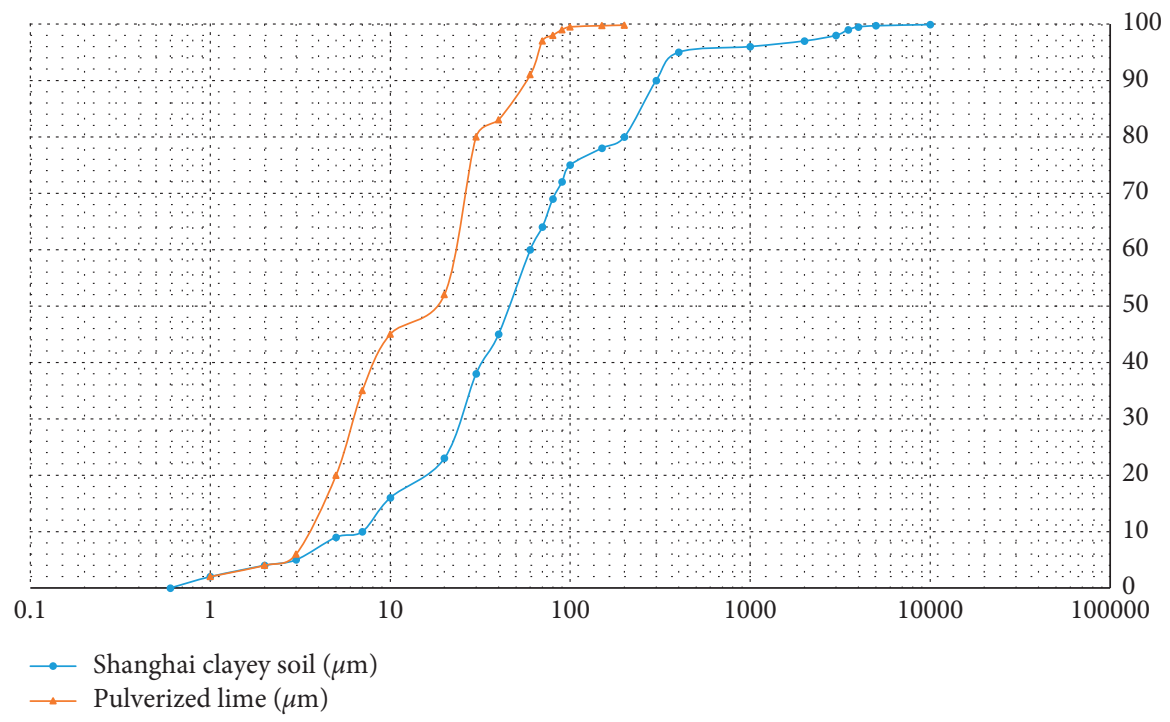

FIGURE 1: Gradation curve of Shanghai clayey soil and pulverized lime (analyzed by Laser Particle Sizer from Malvern Instruments Ltd., Shanghai).

TABle 2: Physical and chemical indexes of pulverized lime.

\begin{tabular}{lccccc}
\hline Appearance & Whiteness & $\mathrm{CaO}(\%)$ & $\mathrm{Ca}(\mathrm{OH})_{2}(\%)$ & $\mathrm{MgO}(\%)$ & Activated CaO $(\%)$ \\
\hline 200 mesh sieve & 90 & 75 & $>6.6$ & 3.61 & $>3.1$ \\
\hline
\end{tabular}

TABLE 3: Key physical and mechanical properties of palm fiber.

\begin{tabular}{llllll}
\hline Average diameter $(\mathrm{mm})$ & Length $(\mathrm{mm})$ & Elastic modulus (MPa) & Tensile strength (MPa) & Relative density & Natural elongation (\%) \\
\hline
\end{tabular}

$\begin{array}{llllll}0.25-0.4 & 4-5 & 800-1900 & 87-166 & 1.24 & 5-21\end{array}$

TABLE 4: Test arrangement of soil samples.

\begin{tabular}{|c|c|c|c|c|c|c|c|}
\hline Test & Type & Sample & Lime (\%) & Palm fiber (\%) & Water content $(\%)$ & Water-lime ratio & Sample size \\
\hline UCT \& UPV & No. 1 & Soil & 0 & 0 & 18 & 0 & 9 \\
\hline UCT \& UPV & No. 2 & Soil-lime & 20.7 & 0 & 57 & 3.3 & 9 \\
\hline UCT \& UPV & No. 3 & Soil-lime-palm fiber & 20.7 & 1 & 57 & 3.3 & 9 \\
\hline DST & No. 1 & Soil & 0 & 0 & 18 & 0 & 9 \\
\hline DST & No. 2 & Soil-lime & 20.7 & 0 & 57 & 3.3 & 9 \\
\hline DST & No. 3 & Soil-lime-palm fiber & 20.7 & 1 & 57 & 3.3 & 9 \\
\hline
\end{tabular}

2.3.2. Ultrasonic Pulse Velocity Test. The ultrasonic pulse velocity (UPV) tests were carried out to evaluate the shear modulus at small or very small strain. The apparatus used is an ultrasonic pulse velocity tester (type PL-200) provided by Suzhou Tuoce instrument Co. Ltd., Jiangsu, China. As UPV is nondestructive, samples could be subjected to UPV tests immediately before UCT. UPV tests followed the standard ASTM D2845 [37]. This test is based on the propagation of ultrasonic waves, whose frequencies are higher than $20 \mathrm{kHz}$, through a cylindrical sample using a pair of transducers coupled to its top and bottom surfaces using a special coupling gel. After waves were received, the time from the moment they were generated to when they reached the receiver (called the wave travelling time) was assessed through the UPV manufacturer's software. The first prominent trough was chosen as the moment of wave arrival. The initial shear modulus can be calculated through the following equation: 


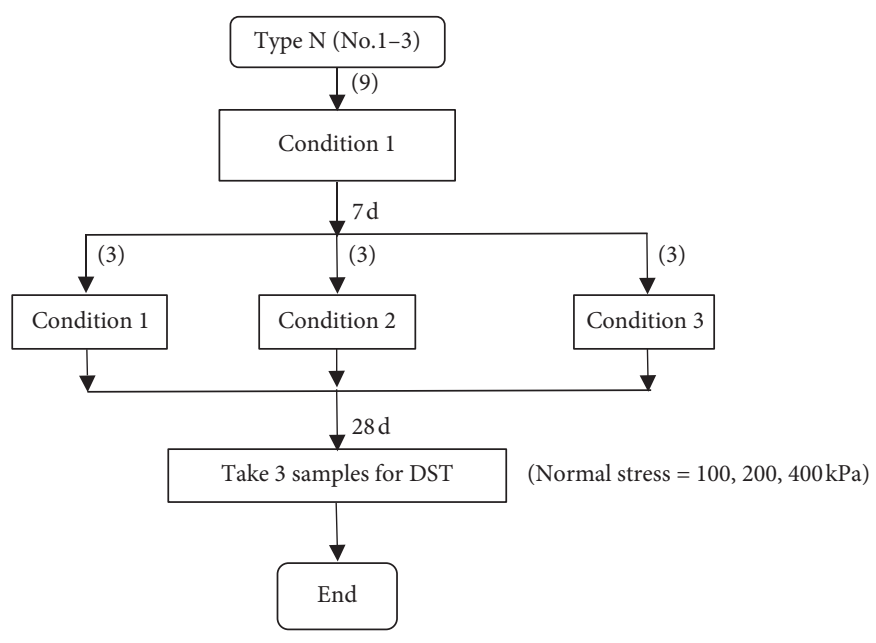

(a)

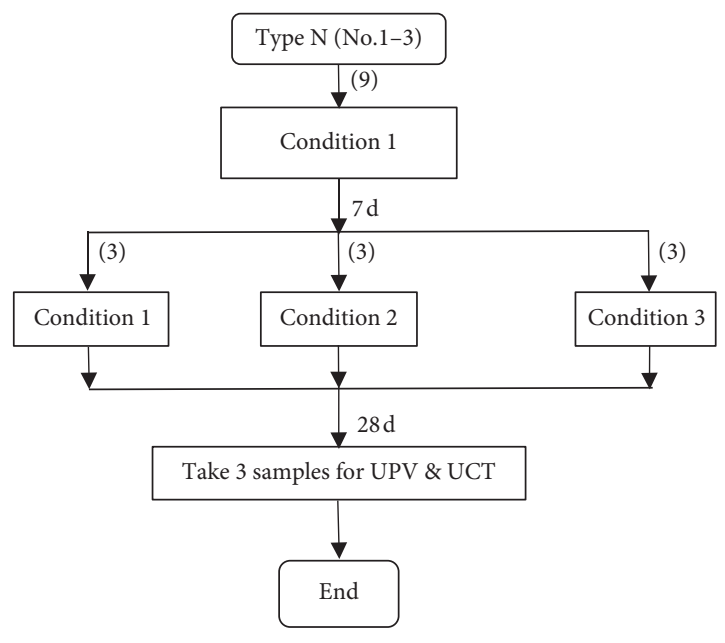

(b)

FIgURE 2: Test scheme in the study. (a) For direct shear test (DST). (b) For ultrasonic pulse velocity test (UPV) and unconfined compressive test (UCT).

$$
G_{0}=\left(\frac{d}{t_{s}}\right)^{2} \times \rho=V_{s}^{2} \times \rho,
$$

where $G_{0}$ is the initial modulus; $d$ is the distance between the two transmitters; $t_{s}$ is shear-wave travelling time; $\rho$ is the bulk unit mass of sample; $V_{s}$ is the shear-wave velocity $\left(d / t_{s}\right)$.

2.3.3. Unconfined Compressive Test. The unconfined compressive tests (UCT) on the soil, soil-lime, and soil-limepalm fiber mixtures were carried out to evaluate the unconfined compressive strength $q_{u}$ (UCS). Unconfined compressive tests were conducted according to ASTM C 39/ C 39M [38]. Owing to specimens with fibers not presenting a clear peak strength, the ultimate strength was determined as the load was kept unchanged for one minute. The apparatus used is a strain-controlled unconfined compressor (PY-3), produced by Nanjing Hydraulic and Electric Instrument Engineering Co. Ltd., with a range of displacement measurement of $0-30 \mathrm{~mm}$ and loading rate of $2.5 \mathrm{~mm} / \mathrm{min}$.

2.3.4. Testing Arrangement. For direct shear tests, nine samples were prepared for each type of sample. For ultrasonic pulse velocity tests and unconfined compressive tests, nine samples were prepared for each type of sample. But each test will be repeated 3 times for reproducible purpose, and their average was taken for later calculation. All the tests are designed to be executed after totally 28-day curing time, regardless of the curing conditions.

All the samples with their molds are first cured in water for 7 days. Then they were divided into 3 groups with each group subjected to Conditions 1, 2, and 3 till day 28, respectively, which are shown as follows:

Condition 1. After initial 7 days of curing in water, specimens with their molds remained immersed in water at a temperature of $20^{\circ} \mathrm{C}$.
Condition 2. After initial 7 days of curing in water, specimens with their molds were subjected to cycles of wetting and drying by alternating periods of soaking in water for 2 days and periods of drying for 1 day in a climatic chamber at a temperature of $20^{\circ} \mathrm{C}$ and a relative humidity of $65 \%$.

Condition 3. After initial 7 days of curing in water, specimens with their molds were placed in a climatic chamber at a temperature of $20^{\circ} \mathrm{C}$ and a relative humidity of $65 \%$.

The 7 and 28 days marked in Figures 3(a) and 3(b) mean the curing time. The numbers in the brackets mean the size of sample. It is important to note that the samples were placed in different curing conditions at an early age before the possible reaction between lime and soil may be complete.

\section{Results and Discussions}

3.1. Shear Strength. To save space, the curves of shear stressdisplacement only for normal stress of $200 \mathrm{kPa}$ are selected for analysis. Those for normal stress of 100 and $400 \mathrm{kPa}$ were not presented. Their development trends are similar to each other. Figures 4(a)-4(c) show the relationships between shear stress and displacement for samples No. 1, 2, and 3 under normal stress of $200 \mathrm{kPa}$ at 3 curing conditions of immersion in water, cyclic wetting-drying, and air curing, respectively. Figures 5(a)-5(c) show the bar graphs of shear strength for 3 types of samples at 3 curing conditions under normal stress of 100,200 , and $400 \mathrm{kPa}$. It can be seen from Figure 3 that generally the shear strengths are highest for samples immersed in water regardless of the type of sample, while those are lowest for air curing and cyclic wettingdrying in between. It shows that the immersed-in-water environment provides the best curing conditions. For sample No. 1 (control sample), the shear strength for immersion in water is 1.41 times higher than that for air curing, with difference of $46 \mathrm{kPa}$. For samples No. 2 and 3, these magnifications are 1.27 and 1.21 , respectively. In addition, the shear strength $(236 \mathrm{kPa})$ of sample No. 3 is far higher 


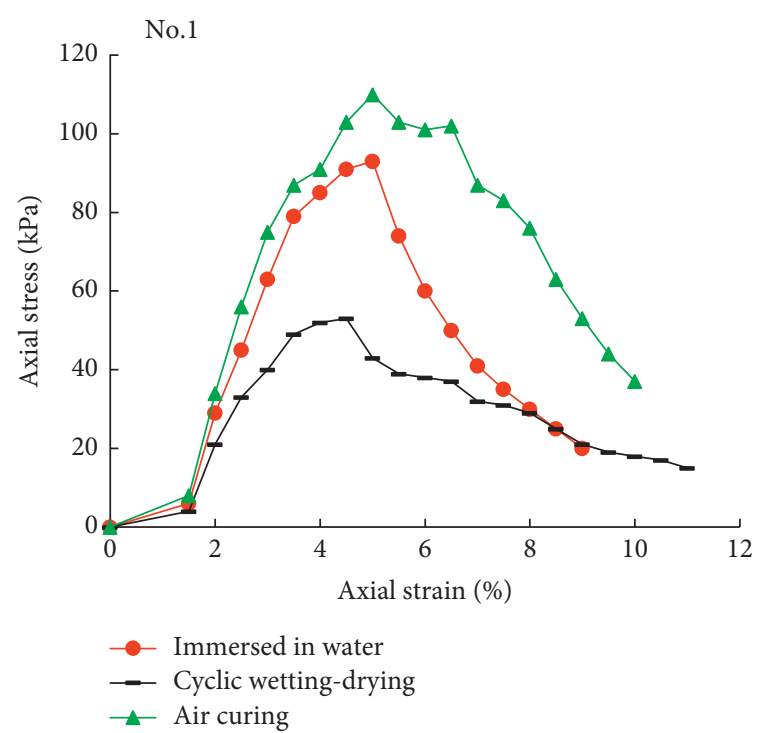

(a)

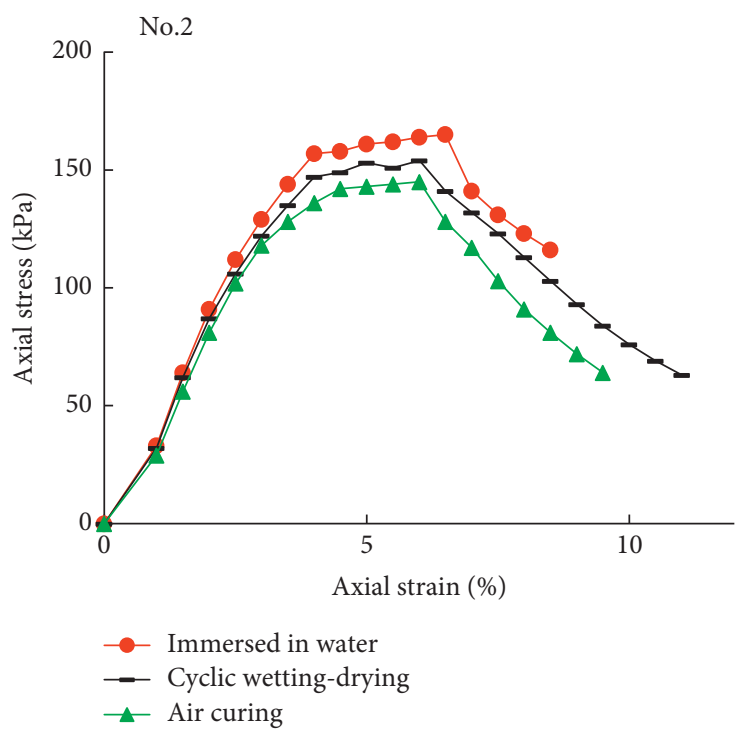

(b)

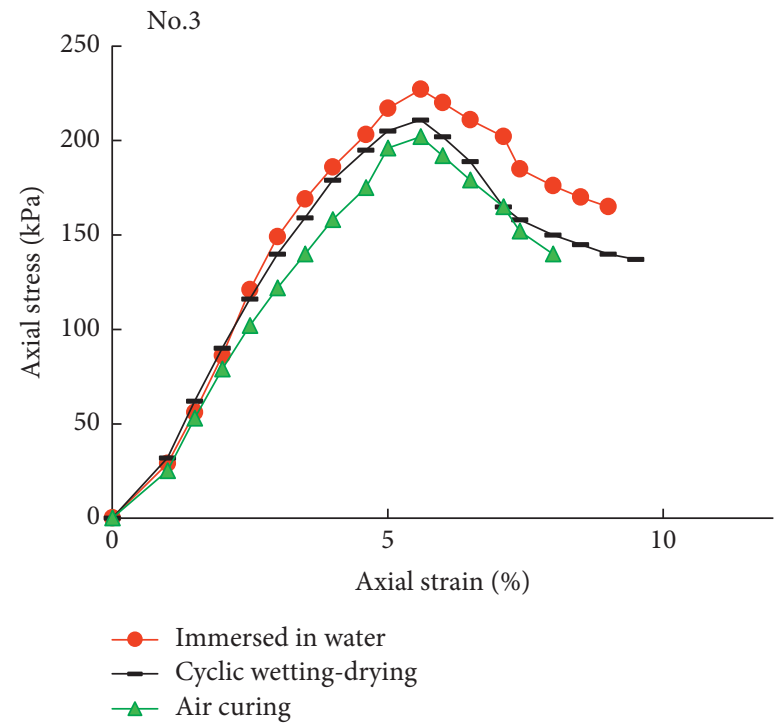

(c)

FIGURE 3: Stress-strain relationship of 3 types of sample. (a) For sample No. 1. (b) For sample No. 2. (c) For sample No. 3.
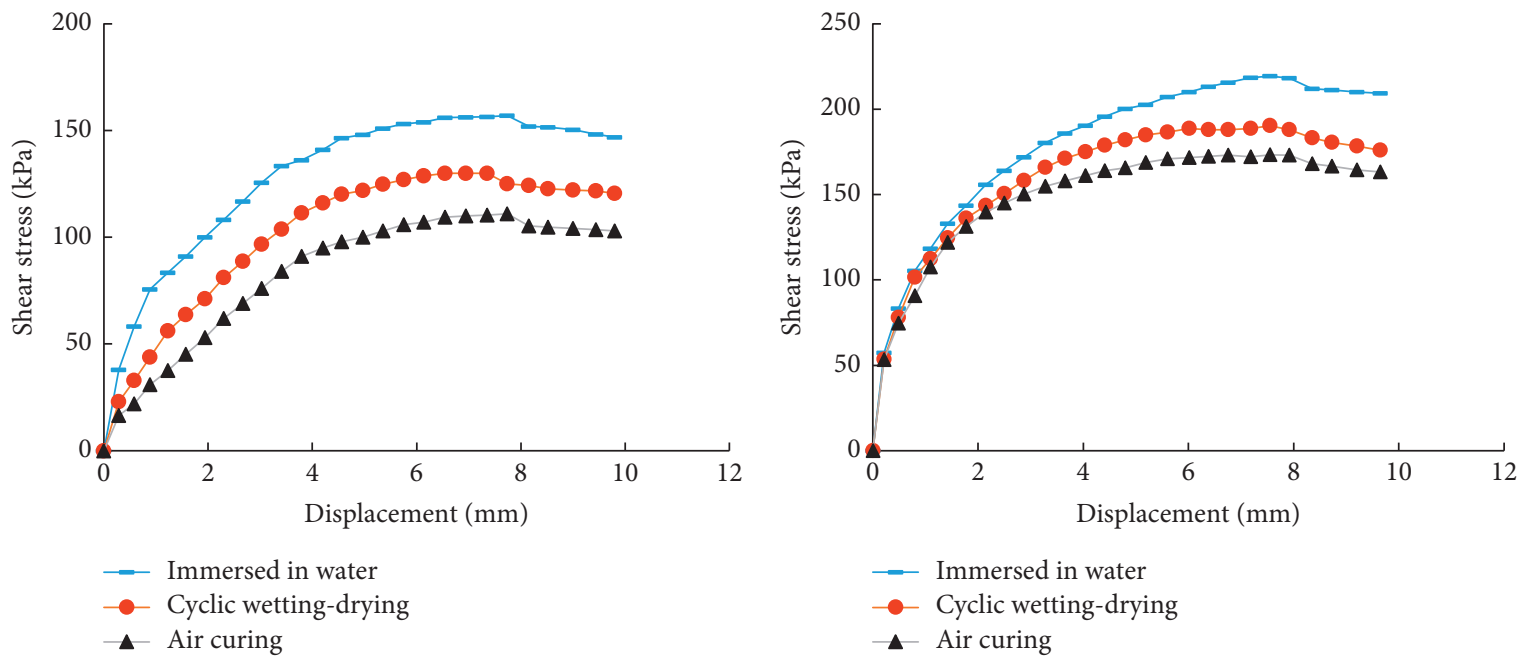

(a) 


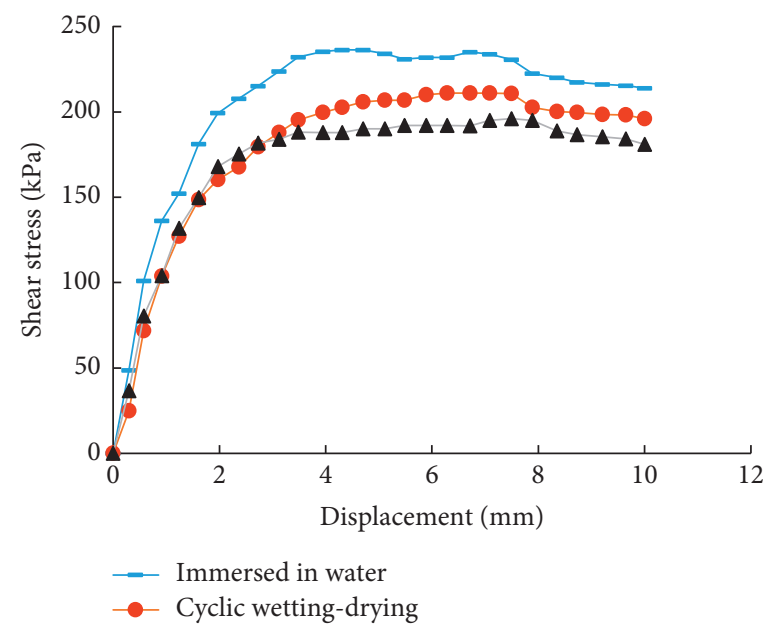

(c)

Figure 4: Relationship between shear stress and displacement. (a) For sample No. 1. (b) For sample No. 2. (c) For sample No. 3.

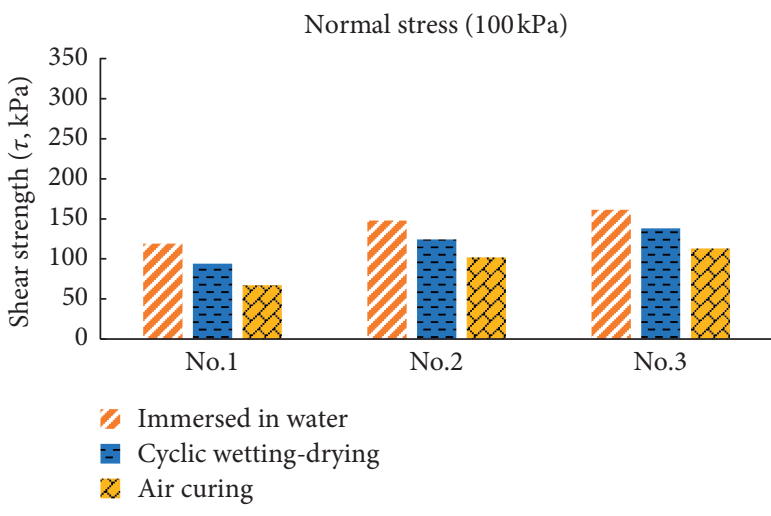

(a)

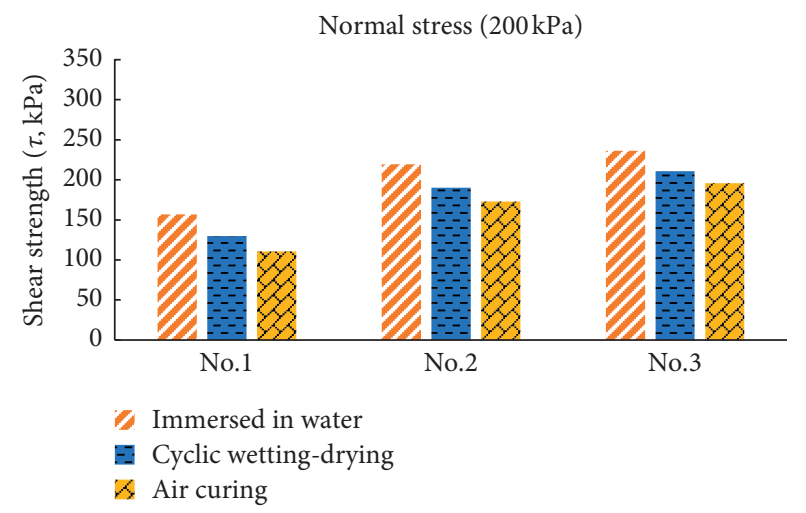

(b)

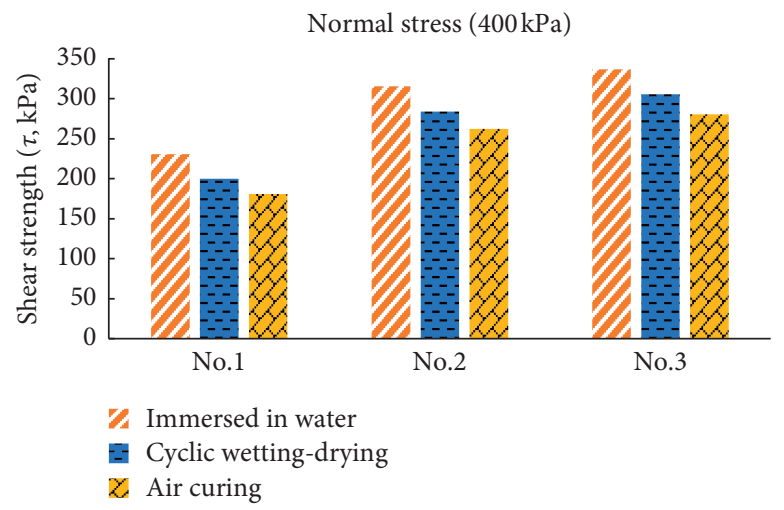

(c)

FiguRE 5: Bar graph for shear strength. (a) For normal stress of $100 \mathrm{kPa}$. (b) For normal stress of $200 \mathrm{kPa}$. (c) For normal stress of $400 \mathrm{kPa}$.

than that $(157 \mathrm{kPa})$ of sample No. 1 in immersed-in-water environment, with approximately 1.5 times higher. This may be fully explained by the bonding functioning of palm fiber and lime. The details for strength are shown in Table 5.

Figures 5(a)-5(c) show a bar graph representing shear strength for different types of soil at 3 curing conditions under normal stress of 100,200 , and $400 \mathrm{kPa}$, respectively.
As a whole, the bigger the normal stress, the higher the shear strength. The shear strength of lime-soil mixture is greater than that of soil, while the shear strength of palm fiber-lime-soil is greater than that of lime soil. This shows that the lime can increase the shear strength of soil as is indicated in many previous studies, and the combination of palm fiber and lime can further increase the shear strength 
TABLE 5: Results from direct shear test.

\begin{tabular}{|c|c|c|c|}
\hline Normal stress $(\mathrm{kPa})$ & Soil type (No.) & Curing condition (time of testing) & $\tau(\mathrm{kPa})$ \\
\hline 100 & 1 & Immersed in water & 119.3 \\
\hline 100 & 1 & Cyclic wetting-drying & 94.3 \\
\hline 100 & 1 & Air curing & 67.2 \\
\hline 200 & 1 & Immersed in water & 157 \\
\hline 200 & 1 & Cyclic wetting-drying & 130 \\
\hline 200 & 1 & Air curing & 111 \\
\hline 400 & 1 & Immersed in water & 231.1 \\
\hline 400 & 1 & Cyclic wetting-drying & 200.1 \\
\hline 400 & 1 & Air curing & 181.1 \\
\hline 100 & 2 & Immersed in water & 147.9 \\
\hline 100 & 2 & Cyclic wetting-drying & 124.4 \\
\hline 100 & 2 & Air curing & 102.1 \\
\hline 200 & 2 & Immersed in water & 219.4 \\
\hline 200 & 2 & Cyclic wetting-drying & 190.3 \\
\hline 200 & 2 & Air curing & 173.3 \\
\hline 400 & 2 & Immersed in water & 315.6 \\
\hline 400 & 2 & Cyclic wetting-drying & 284.2 \\
\hline 400 & 2 & Air curing & 263.3 \\
\hline 100 & 3 & Immersed in water & 161.3 \\
\hline 100 & 3 & Cyclic wetting-drying & 138.4 \\
\hline 100 & 3 & Air curing & 113.1 \\
\hline 200 & 3 & Immersed in water & 236.3 \\
\hline 200 & 3 & Cyclic wetting-drying & 211.0 \\
\hline 200 & 3 & Air curing & 196.1 \\
\hline 400 & 3 & Immersed in water & 337.0 \\
\hline 400 & 3 & Cyclic wetting-drying & 305.9 \\
\hline 400 & 3 & Air curing & 280.9 \\
\hline
\end{tabular}

of soil significantly. Furthermore, the environment of air curing is the worst of 3 conditions. This may be rationally explained by the hydration of lime that tends to need sufficient water. Otherwise, the lack of water may disturb the formation of shear strength. The bonding functions between palm fiber and soil particles further improve the strength of soil. However, the cyclic wetting-drying environment may cause the loss of soil particle more or less, which may be the reason why the strength at cyclic wettingdrying is less than that at immersion in water. However, the cyclic wetting-drying can still provide certain amount of water; therefore, the strength at wetting-drying condition is greater than that at air curing. The highest shear strength comes from sample No. 3 at the condition of immersion in water, while the lowest strength is from sample No. 1 at condition of air curing. For normal stress of $400 \mathrm{kPa}$, the shear strength $(337 \mathrm{kPa})$ of sample No. 3 is 1.46 times higher than that $(231 \mathrm{kPa})$ of sample No. 1 and 1.07 times higher than that $(316 \mathrm{kPa})$ of sample No. 2 at curing condition of immersion in water. The shear strength $(316 \mathrm{kPa})$ of sample No. 2 is 1.37 times higher than that $(231 \mathrm{kPa})$ of sample No. 1 . This shows the lime has higher effect on shear strength than palm fiber.

3.2. Cohesion and Internal Friction Angle. Table 6 shows the cohesion and its corresponding internal friction angle of 3 types of sample under 3 curing conditions. Sample No. 3 has the highest shear strength with the highest cohesion and internal friction angle. The internal friction angle $\left(29.9^{\circ}\right)$ of sample No. 3 is increased significantly compared with that $\left(20.4^{\circ}\right)$ of sample No. 1 , with a percent increase of $47 \%$, but it only has a slight increase compared with that $\left(28.7^{\circ}\right)$ of sample No. 2, with a percent increase of $4 \%$. It means that, under curing condition of immersion in water, addition of palm fiber cannot substantially increase the internal friction angle of soil, but it can increase cohesion significantly. Compared with cohesion of sample No. 1, the cohesions of samples No. 2 and 3 are increased by 21 and 35\%, respectively. For curing conditions of cyclic wetting-drying and air curing, there are comparative change rules, which can be seen from Table 6. For different curing conditions, the cohesion and internal friction angle under immersion in water have the highest value regardless of the sample type. But there are minimum values with air curing condition, with cyclic wetting-drying in between. This shows that immersion in water is the best curing condition regardless of the sample type and that cyclic wetting-drying condition has a destructive effect on the strength of soil. The air curing condition can usually cause cracks on the surface of sample, which leads to the decrease in strength.

\subsection{Unconfined Compressive Strength (UCS).} Figures 3(a)-3(c) show the relationship between stress and strain under 3 curing conditions for No. 1-3 types of soil. It can be seen from Figure 3(a), for control sample (No. 1), that air curing samples have the highest unconfined compressive strength $(110 \mathrm{kPa})$, while the samples with cyclic wettingdrying have the lowest unconfined compressive strength $(53 \mathrm{kPa})$. Their difference is approximately $57 \mathrm{kPa}$, with UCS 
TAвLE 6: Cohesion and internal friction angle.

\begin{tabular}{|c|c|c|c|c|c|c|}
\hline \multirow[b]{2}{*}{ Sample } & \multicolumn{2}{|c|}{ Immersed in water } & \multicolumn{2}{|c|}{ Cyclic wetting-drying } & \multicolumn{2}{|c|}{ Air curing } \\
\hline & Cohesion $(\mathrm{kPa})$ & $\begin{array}{c}\text { Internal friction } \\
\text { angle }\left({ }^{\circ}\right)\end{array}$ & Cohesion $(\mathrm{kPa})$ & $\begin{array}{c}\text { Internal friction } \\
\text { angle }\left({ }^{\circ}\right)\end{array}$ & Cohesion $(\mathrm{kPa})$ & $\begin{array}{c}\text { Internal friction } \\
\text { angle }\left({ }^{\circ}\right)\end{array}$ \\
\hline 1 & 82.3 & 20.4 & 59.2 & 19.4 & 32.2 & 20.6 \\
\hline 2 & 99.8 & 28.7 & 77.5 & 27.6 & 57.1 & 27.7 \\
\hline 3 & 111 & 29.9 & 91 & 28.7 & 70.8 & 28.4 \\
\hline
\end{tabular}

under air curing being 108\% higher than that of cyclic wetting-drying condition approximately. The unconfined compressive strength with immersion in water is in between. This means that, for the control sample, air curing condition has significantly positive effect on UCS of samples that contain no additives, and cyclic wetting-drying is the worst curing condition. However, for samples No. 2 and 3, UCSs are highest under condition of immersion in water, while the UCS with air curing is lowest, with cyclic wetting-drying in between. This may be the functionality of lime that needs sufficient water to strengthen the soil. For samples No. 2 and 3 , the UCSs at condition of immersion in water are $14 \%$ and $12 \%$ higher than those of air curing condition, respectively. These differences are far less than that in control sample, that is, $108 \%$. This means that the additives of lime and palm fiber can effectively offset the effect caused by severe environment. With horizontal comparison, the UCSs for sample No. 3 are $144 \%, 298 \%$, and $84 \%$ higher than those for sample No. 1 under conditions of immersion in water, cyclic wettingdrying, and air curing, respectively. Comparing between samples No. 2 and 3, the UCSs for sample No. 3 are $38 \%$, $37 \%$, and $39 \%$ higher than those for sample No. 2 under 3 curing conditions, respectively. From above data, for samples already reinforced with lime, it can be inferred that UCS increase caused by additive of palm fiber is almost independent of curing condition. But, for pure control samples without any additive, the law for UCS increase caused by palm fiber and lime cannot be certainly asserted by curing condition, as is shown in Figure 6.

3.4. Shear Stiffness $\left(G_{0}\right)$. Figure 7 shows the bar graph of sample stiffness $\left(G_{0}\right)$ for samples No. 1-3 under 3 curing conditions. Stiffness expresses the elastic behavior of samples at small or very small strain. It can be seen from Figure 7 that, regardless of the sample type, the stiffness at condition of immersion in water is highest, while it is lowest with air curing condition. For sample No. 1, the stiffness under condition of immersion in water is $185 \%$ higher than that under condition of air curing. For samples No. 2 and 3, these figures are $105 \%$ and $96 \%$, respectively. This shows that the samples mixed with lime and palm fiber have stronger resistance against environmental change. For curing condition of immersion in water, $G_{0}$ of sample No. 2 is increased by $110 \%$ compared with that of sample No. 1 . This suggests that the lime can substantially increase the stiffness of sample which may be closely related to the sufficient hydration of lime. However, $G_{0}$ of sample No. 3 is lower than that of sample No. 2, a decrease of $14 \%$ instead. This shows that palm fiber has the effect of reducing the stiffness of sample.
Figure 8 shows the ratio of $G_{0} / q_{u}$ of samples No. 1-3 under 3 curing conditions. The ratio of $G_{0} / q_{u}$ indicates the relative change speed of $G_{0}$ to $q_{u}$. Except sample No. 1 that occurs abnormally in which the ratio of $G_{0} / q_{u}$ is maximized under the condition of cyclic wetting-drying, for sample No. 2, the ratio of $G_{0} / q_{u}$ is maximized under condition of immersion in water, which is $14 \%$ and $80 \%$ higher than those under cyclic wetting-drying and air curing, respectively. For sample No. 3, the ratio of $G_{0} / q_{u}$ is maximized under the condition of immersion in water, which is $16 \%$ and $75 \%$ higher than those under the cyclic wetting-drying and air curing, respectively. This means that the increase speed of $G_{0}$ compared to that of $q_{u}$ is faster under condition of immersion in water than under the cyclic wetting-drying and air curing condition. In addition, the law of ratio of $G_{0} / q_{u}$ can also allow us to roughly predict $G_{0}$ based on $q_{u}$ in similar conditions or predict $q_{u}$ based on $G_{0}$, which can reduce the cost needed to conduct the related experiments to determine the targeted parameters.

3.5. Relation among $c, q_{w}$ and $G_{0}$. The cohesion $c$ of sample was selected as a key parameter to compare it with the unconfined compressive strength $q_{u}$ and shear modulus $G_{0}$ (stiffness) at small or very small strains because it can remain almost constant under the 3 curing conditions as shown in the above analysis. The shear strength $(\tau)$ of samples is strongly dependent on the normal stress, and the internal friction angle $(\varphi)$ was almost not affected by the change of curing condition; therefore $\tau$ and $\varphi$ are not used as comparison parameters. Figure 9 shows the bar graph of $c / q_{u}$ ratio for samples No. 1-3 under 3 curing conditions. The ratio of $c / q_{u}$ indicates the relative change speed of $c$ to $q_{u}$. Except sample No. 1 that occurs abnormally in which the ratio of $c / q_{u}$ is maximized under the condition of cyclic wetting-drying, for sample No. 2, the ratio of $c / q_{u}$ is maximized under the condition of immersion in water, which is $20 \%$ and $54 \%$ higher than those under cyclic wetting-drying and air curing, respectively. For sample No. 3, the ratio of $c / q_{u}$ is maximized under the condition of immersion in water, which is $13 \%$ and $40 \%$ higher than those under cyclic wetting-drying and air curing, respectively. This means that the increase speed of $c$ compared to that of $q_{u}$ is faster under condition of immersion in water than under the cyclic wetting-drying and air curing condition. In addition, the law of ratio of $c / q_{u}$ can also allow us to roughly predict $c$ based on $q_{u}$ in similar conditions or predict $q_{u}$ based on $c$, which can reduce the cost needed to conduct the related experiments to determine the desired indexes.

The bar graph of $c / G_{0}$ ratio for samples No. 1-3 under 3 curing conditions is shown in Figure 10. It can be seen from the bar graph that there generally is no big variation in $c / G_{0}$ 


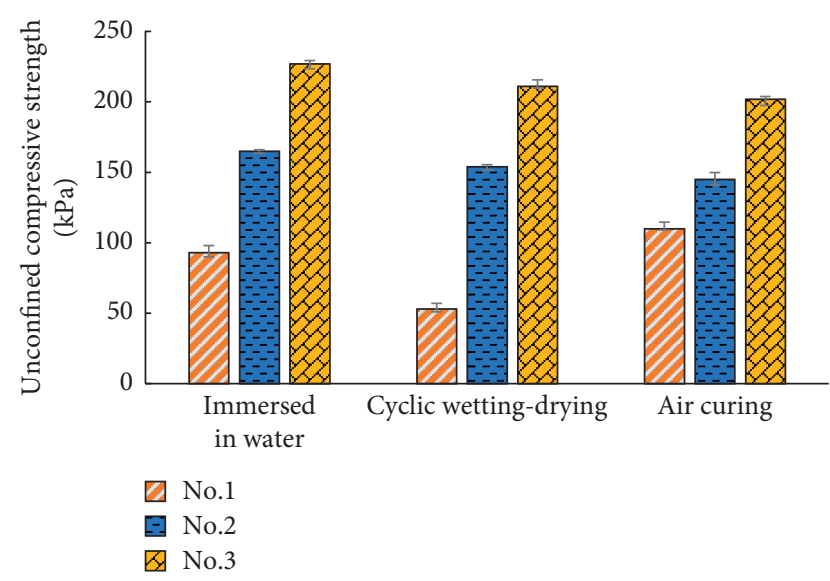

FIGURE 6: Effects of curing conditions on unconfined compressive strength $q_{u}$.

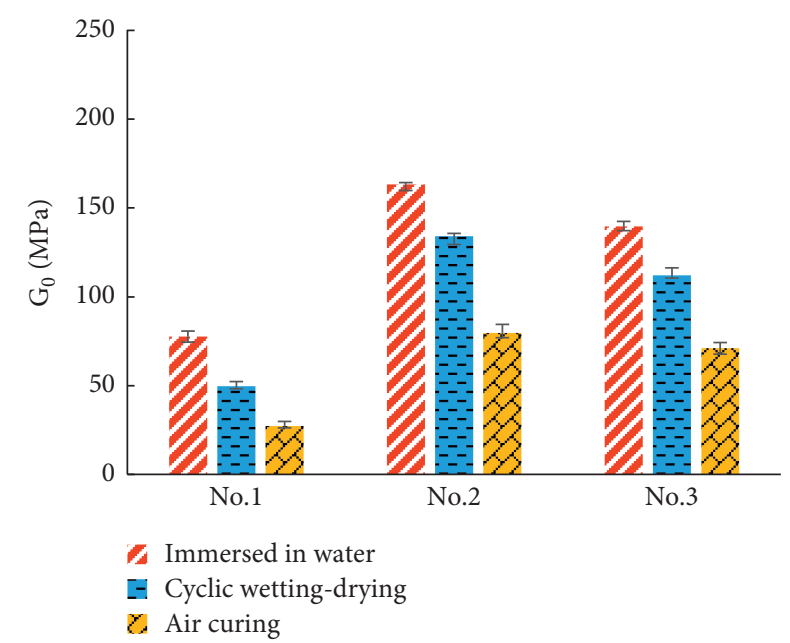

Figure 7: Bar graph of sample stiffness for samples No. 1-3 under 3 curing conditions.

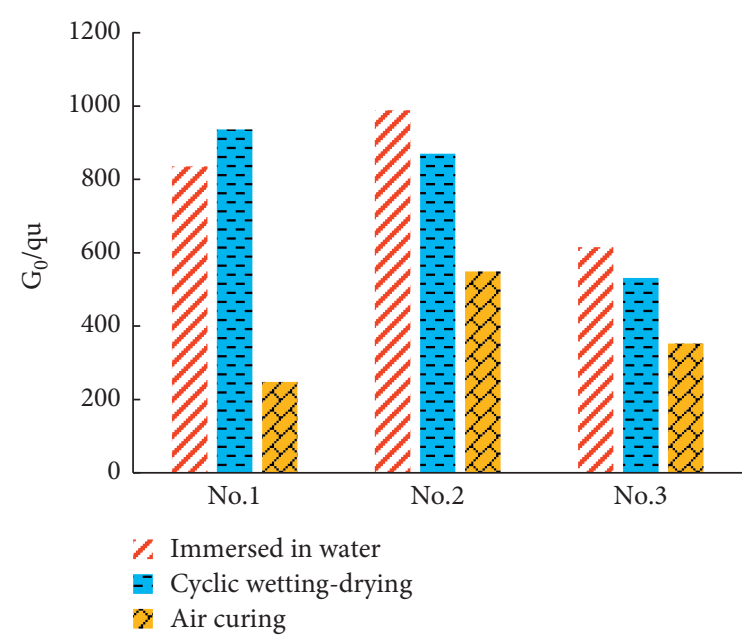

Figure 8: Ratio of $G_{0} / q_{u}$ of samples no. 1-3 under 3 curing conditions.

when curing condition is changed from one process to another. Only the type of sample can determine the ratio of $c / G_{0}$. For samples No. 2 and 3, the $c / G_{0}$ ratios are slightly

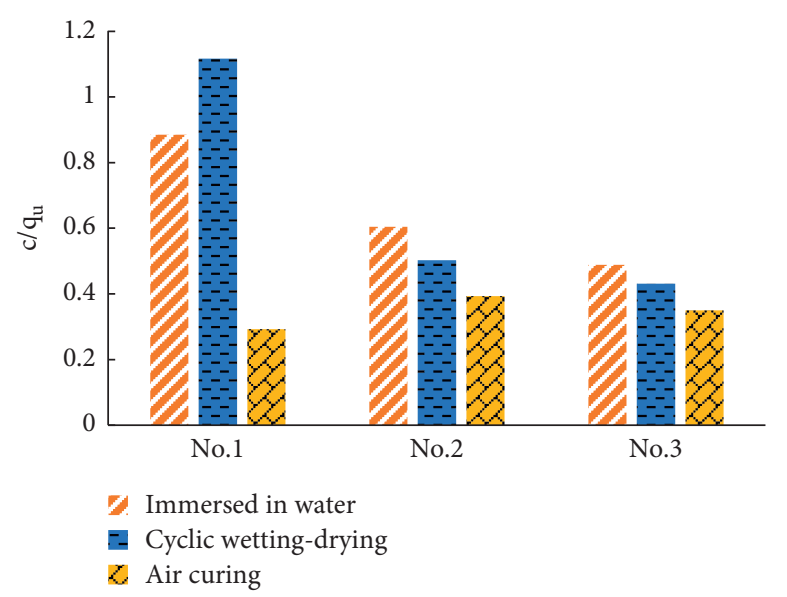

FIgURE 9: Bar graph of $c / q_{u}$ ratio for samples No. 1-3 under 3 curing conditions.

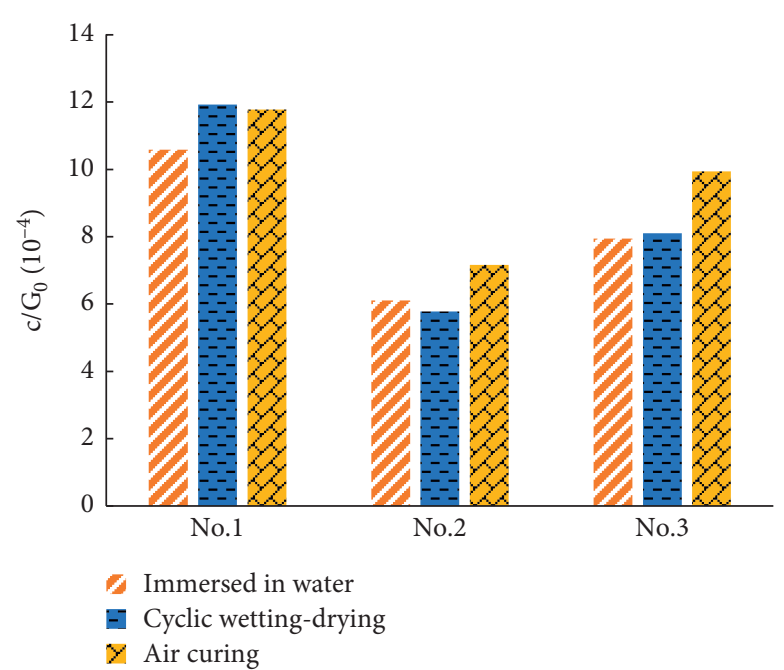

FIgURE 10: Bar graph of $c / G_{0}$ ratio for samples No. 1-3 under 3 curing conditions.

higher under air curing than under immersed in water and cyclic wetting-drying. It means that the increase speed of $c$ under air curing is slightly higher than that under immersion in water and air curing. Nevertheless, as their differences are so small (differences between $c / G_{0}$ ratios $<2 \times 10^{-4}$ ), it may be as well assumed to ignore them so that the ratios of $c / G_{0}$ may be considered approximately unchanged under 3 curing conditions for any type of sample. If applicable, the relatively fixed ratio of $c / G_{0}$ for a type of sample can be used, namely, to roughly predict the cohesion $(c)$ based on $G_{0}$ or to predict $G_{0}$ on $c$, which may reduce the cost of tests needed to obtain these key parameters in design and construction of related civil engineering projects because they almost remain constant under severe environment.

\section{Conclusion}

In consideration of being copiously available and inexpensive in economy with palm fiber in south China area, it is pondered needful and applicable to employ palm fiber as 
admixture to promote soil behavior for a good deal of geotechnical engineering projects. In addition, palm fiber is also widely regarded as environment-friendly and green material that is appropriate for the development trend in the world. In the present study, the direct shear test, the ultrasonic pulse velocity tests, and the unconfined compressive test were carried out on soil mixed with different content of lime and palm fiber under varied curing environments. The main conclusions are presented as follows:

(1) Immersion in water is the best curing environment for shear strength formation regardless of the type of soil. Lime can substantially increase the shear strength of sample but palm fiber can only slightly increase the shear strength under any curing environment.

(2) Curing conditions have substantial effect on cohesion. Immersion in water is the best and air curing is the worst for cohesion increase of samples. Although lime can significantly increase the cohesion of samples, it cannot be neglected for the effect of palm fiber in promoting the cohesion of samples. Nevertheless, there is very little effect of curing condition on internal friction angle for a fixed type of sample. Lime has significant effect on increase of internal friction angle; on the contrary, palm fiber has only limited effect regardless of the curing environments.

(3) There is only limited effect of curing conditions on unconfined compressive strength for lime-soil or lime-palm fiber-soil mixture. In other words, for samples already reinforced with lime, UCS increase caused by additive of palm fiber is almost independent of curing condition.

(4) Lime can increase both $G_{0}$ and $q_{u}$, but palm fiber can slightly reduce $G_{0}$, although it can also increase $q_{u}$. For lime-soil and lime-palm fiber-soil mixture, $G_{0} / q_{u}$ ratio is the highest under the immersion in water condition. It means that, compared with $q_{u}$, the increase speed of $G_{0}$ under condition of immersion in water is the fastest of the 3 curing conditions.

(5) For lime-soil or lime-palm fiber-soil mixture, although $c / q_{u}$ under immersion in water is the highest of the 3 curing conditions, the difference between the maximum and minimum $c / q_{u}$ is not very big; therefore it can be concluded that samples mixed with lime and palm fiber have stronger resistance against change of curing condition.

(6) $c / G_{0}$ for any type of sample remains almost constant under different curing conditions. It demonstrates that $c$ and $G_{0}$ possess the comparative development trend under different curing environment.

Even though there were a lot of researches on effect of lime and palm fiber on mechanical behaviors of soil, few researches have been centered on influence of curing environment on soil quality. Thus, the present research appears to be more far between. Well understanding of the enhancing mechanism of lime and palm fiber on soil characteristics with curing condition is of key role not only in design, construction, support, protection, and maintenance of a mass of relevant geotechnical engineering projects but also in environmental protection and sustainable development.

\section{Data Availability}

All data are available from the corresponding author upon request: qujiliqwq@163.com.

\section{Conflicts of Interest}

The authors declare that they have no conflicts of interest.

\section{Acknowledgments}

The authors firstly thank Shanghai Shiyi Information Management Co., Ltd., for providing financial support (Grant no. 1y-00-307-206). The authors also thank Huang Xiaoru M.E. for her contribution to the work of analysis in particle size distribution of soil, Liang Jun M.E. for his help in a variety of laboratory experiments, and Zhu Hao M.E. for his assistance in data processing and graph drawing.

\section{References}

[1] X. M. Zhou, L. Y. Yuan, and J. Q. Cai, "Analysis of the distribution characteristics of soft soils in Shanghai and the examples of soft soil foundation deformation," Shanghai Geology, vol. 4, no. 6, pp. 9-61, 2005.

[2] X. Li, "Late Cenozoic stratigraphic division and sedimentary environment evolution in Shanghai," Shanghai Geology, vol. 30, no. 1, pp. 1-7, 2009.

[3] S. L. Gong, C. Li, and S. L. Yang, "The microscopic characteristics of Shanghai soft clay and its effect on soil body deformation and land subsidence," Environmental Geology, vol. 56, no. 6, pp. 1051-1056, 2009.

[4] S. YangLi and L. H. Chen, Study on Minimum Reinforcement Ratio of Hydraulic Reinforced Concrete Members, vol. 1, pp. 44-51, Journal of Hohai University, Jiangsu, China, 1992.

[5] A. J. Puppala and C. Musenda, "Effects of fiber reinforcement on strength and volume change in expansive soils," Transportation Research Record: Journal of the Transportation Research Board, vol. 1736, no. 1, pp. 134-140, 2000.

[6] H. Tan, F. Chen, J. Chen, and Y. Gao, "Direct shear tests of shear strength of soils reinforced by geomats and plant roots," Geotextiles and Geomembranes, vol. 47, no. 6, pp. 780-791, 2019.

[7] M. K. Tabrizi, S. Abrishami, E. S. Hosseininia, S. Sharifi, and S. Ghorbani, "Experimental investigation on the behavior of fine-grained soils containing waste rubber tires under repeated and static loading using direct shear apparatus," Construction and Building Materials, vol. 223, pp. 106-119, 2019.

[8] F. Ghorbani, F. Bateni, and M. Azmi, "Performance evaluation of silty sand reinforced with fibres," Geotextiles and Geomembranes, vol. 28, no. 1, pp. 93-99, 2010.

[9] M. Mirzababaei, A. Arulrajah, S. Horpibulsuk, and M. Aldava, "Shear strength of a fibre-reinforced clay at large shear displacement when subjected to different stress histories," Geotextiles and Geomembranes, vol. 45, no. 5, pp. 422-429, 2017.

[10] E. Amiri, H. Emami, M. R. Mosaddeghi, and A. R. Astaraei, "Shear strength of an unsaturated loam soil as affected by 
vetiver and polyacrylamide," Soil and Tillage Research, vol. 194, p. 104331, 2019.

[11] A. Jotisankasa and N. Rurgchaisri, "Shear strength of interfaces between unsaturated soils and composite geotextile with polyester yarn reinforcement," Geotextiles and Geomembranes, vol. 46, no. 3, pp. 338-353, 2018.

[12] E. M. B. De Guzman, D. Stafford, M. C. Alfaro, G. Doré, and L. U. Arenson, "Large-scale direct shear testing of compacted frozen soil under freezing and thawing conditions," Cold Regions Science and Technology, vol. 151, pp. 138-147, 2018.

[13] Y. K. Wu, B. Niu, and X. S. Sang, "Experimental study on mechanical properties of randomly distributed sisal fiber reinforced soil," Hydrogeology and Engineering Geology, vol. 39, no. 6, pp. 77-81, 2012.

[14] J. L. Qu, D. X. Zhao, and B. B. Li, "Effects of reinforcement conditions on the strength of palm fiber reinforced soil," Industrial Construction, vol. 45, no. 3, pp. 115-119, 2015.

[15] T. Yilmaz, B. Ercikdi, K. Karaman, and G. Külekçi, "Assessment of strength properties of cemented paste backfill by ultrasonic pulse velocity test," Ultrasonics, vol. 54, pp. 13861394, 2014.

[16] J. Carrillo, J. Ramirez, and J. Lizarazo-Marriaga, "Modulus of elasticity and Poisson's ratio of fiber-reinforced concrete in Colombia from ultrasonic pulse velocities," Journal of Building Engineering, vol. 23, pp. 18-26, 2019.

[17] G. Trtnik, F. Kavčič, and G. Turk, "Prediction of concrete strength using ultrasonic pulse velocity and artificial neural networks," Ultrasonics, vol. 49, no. 1, pp. 53-60, 2009.

[18] A. L. Kouby, A. Guimond-Barrett, P. Reiffsteck, and A. Pantet, "Influence of drying on the stiffness and strength of cementstabilized soils," Geotechnical and Geological Engineering, vol. 1, pp. 1-12, 2017.

[19] H. Åhnberg, "Consolidation stress effects on the strength of stabilised Swedish soils," Proceedings of the Institution of Civil Engineers-Ground Improvement, vol. 10, no. 1, pp. 1-13, 2006.

[20] H. Âhnberg and S. E. Johansson, "Increase in strength with time in soils stabilized with different types of binder in relation to the type and amount of reaction products," in Proceedings of the 4th International Conference on Deep Mixing, Swedish Geotechnical Institute, Stockholm, Sweden, pp. 195-202, May 2005.

[21] H. Åhnberg, S.-E. Johansson, H. Pihl, and T. Carlsson, "Stabilising effects of different binders in some Swedish soils," Proceedings of the Institution of Civil Engineers-Ground Improvement, vol. 7, no. 1, pp. 9-23, 2003.

[22] A. M. Carlsson, H. Mroueh, and L. Lancelot, "Experimental investigation of cement treated sand behavior under triaxial test," Geotechnical and Geological Engineering, vol. 30, no. 1, pp. 129-143, 2012.

[23] N. C. Consoli, D. Foppa, L. Festugato, and K. S. Heineck, "Key parameters for strength control of artificially cemented soils," Journal of Geotechnical and Geoenvironmental Engineering, vol. 133, no. 2, pp. 197-205, 2007.

[24] N. C. Consoli, R. C. Cruz, M. F. Floss, and L. Festugato, "Parameters controlling tensile and compressive strength of artificially cemented sand," Journal of Geotechnical and Geoenvironmental Engineering, vol. 136, no. 5, pp. 759-763, 2010.

[25] S. Horpibulsuk, W. Katkan, W. Sirilerdwattana, and R. Rachan, "Strength development in cement stabilized low plasticity and coarse grained soils: laboratory and field study," Soils and Foundations, vol. 46, no. 3, pp. 351-366, 2006.
[26] N. Miura, S. Horpibulsuk, and T. S. Nagaraj, "Engineering behavior of cement stabilized clay at high water content," Soils and Foundations, vol. 41, no. 5, pp. 33-45, 2001.

[27] T. S. Tan, T. L. Goh, and K. Y. Yong, "Properties of Singapore marine clays improved by cement mixing," Geotech Test, vol. 25, no. 4, pp. 422-433, 2002.

[28] A. Porbaha, S. Shibuya, and T. Kishida, "State of the art in deep mixing technology. Part III:geomaterial characterization," Proceedings of the Institution of Civil Engineers - Ground Improvement, vol. 4, no. 3, pp. 91-110, 2000.

[29] F. Szymkiewicz, A. Guimond-Barrett, A. L. Kouby, and P. Reiffsteck, "Influence of grain size distribution and cement content on the strength and aging of treated sandy soils," European Journal of Environmental and Civil Engineering, vol. 16, no. 7, pp. 882-902, 2012.

[30] M. Terashi, "Theme lecture: deep mixing method-brief state of the art," in Proceedings of the 14th ICSMFE, pp. 2475-2478, Hamburg, Germany, September 1997.

[31] T. H. Zhang, X. L. Li, L. Cheng et al., "Performance and application status of palm fiber," Industrial Textiles, vol. 28, no. 6, pp. 35-38, 2010.

[32] CEN, ISO, TS 17892-4, Geotechnical Investigation and Testing-Laboratory Testing of Soil-Part 4: Determination of Particle Size Distribution, European Committee for Standardization, Brussels, Belgium, 2005.

[33] CEN, ISO, TS 17892-12, Geotechnical Investigation and Testing-Laboratory Testing of Soil-Part 12: Determination of Atterberg Limits, European Committee for Standardization, Brussels, Belgium, 2005.

[34] CDIT (Coastal Development Institute of Technology), The Deep Mixing Method: Principle, Design and Construction, A.A. Balkema, Lisse, Netherlands, 2002.

[35] Euro Soil Stab, Design Guide: Soft Soil Stabilisation. EuroSoilStab: Development of Design and Construction Methods to Stabilise Soft Organic Soil, CT97-0351, European Commission, Industrial and Materials Technologies Programme (RiteEuRam III), Brussels, Belgium, 2002.

[36] JTG E40-2007, Test Methods of Soils for Highway Engineering. T 0141-1993, Ministry of Communications of the People Republic of China, Beijing, China, 2007.

[37] ASTM D2845, Standard Test Method for Laboratory Determination of Pulse Velocities and Ultrasonic Elastic Constants of Rock, American Society for Testing Materials, West Conshohocken, PA, USA, 2008.

[38] ASTM C 39/C 39M, Standard Test Method for Compressive Strength of Cylindrical Concrete Specimens, American Society for Testing Materials, West Conshohocken, PA, USA, 2018. 